\title{
Nasopharyngeal bacterial carriage and antimicrobial resistance in underfive children with community acquired pneumonia
}

\author{
Cissy B. Kartasasmita, ${ }^{1}$ Heda Melinda Duddy, ${ }^{1}$ Sunaryati Sudigdoadi, ${ }^{2}$ Dwi Agustian, ${ }^{3}$ Ina Setiowati, ${ }^{3}$ \\ Tri Hanggono Ahmad, ${ }^{3}$ Ramdan Panigoro ${ }^{3}$ \\ Departments of Child Health, ${ }^{1}$ Microbiology, ${ }^{2}$ and The Research Unit, ${ }^{3}$ Medical School, Padjadjaran University \\ Hasan Sadikin General Hospital, Bandung
}

\begin{abstract}
Lung puncture is the best way to determine the etiology of pneumonia since it yields the highest rate of positive cultures. However, this procedure is difficult, especially for a study in the community. According to WHO, isolates to be tested for antimicrobial resistance in the community should be obtained from nasopharyngeal (NP) swabs. Previous studies support the use of NP isolates to determine antimicrobial resistance patterns of isolates from children with pneumonia. The aim of our study was to know the bacterial patterns of the nasopharynx in underfive children with community acquired pneumonia and their antimicrobial resistance. The study was carried out in 4 Primary Health Clinics in Majalaya sub-district, Bandung, Indonesia. All underfives with cough or difficult breathing and classified as having non-severe pneumonia (WHO guidelines), were included in the study. Nasopharyngeal swabs (CDC/WHO Manual) were obtained by the doctor, the swabs were placed in Amies transport medium and stored in a sterile jar before taken to the laboratory in the same day. All children were treated with co-trimoxazole. During the nine month study, 698 children with clinical signs of non-severe pneumonia were enrolled. About $25 \%$ of the nasopharyngeal specimens yielded bacterial isolates; the two most frequently found were $S$. pneumoniae and S. epidermidis. The antimicrobial resistance test to co-trimoxazole showed $48.2 \%$ S. pneumoniae strain had full resistance and $32.7 \%$ showed intermediate resistance to co-trimoxazole. This result is almost similar to other studies from Asian countries. It seems that $H$. influenzae is not a problem in the study area; however, further studies are needed. [Paediatr Indones 2001; 41:292-295]
\end{abstract}

Key words: community acquired pneumonia, nasopharyngeal carriage, S. pneumoniae, antimicrobial resistance

PNeUmonia COULD BE CAUSED BY A VARIETY OF AGENTS, and each requiring a different treatment approach. The majority of lower respiratory infections during

Correspondence: Cissy B. Kartasasmita, MD, PhD Department of Child Health Padjadjaran University Hasan Sadikin General Hospital, Jalan Pasteur 38, Bandung 40161, Tel/Fax . 62 (22) 2032216,email: cbkarta@bdg.centrin.net.id

The article has been presented as oral presentation in the 10th ASEAN Pediatric Federation Conference \& 22nd Annual Congress of the Malaysian Paediatric Association, June 2000

This study was supported by the ICDC Project, Directorate General of Infectious Diseases and Environmental Health, Department of Health, Republic of Indonesia. infancy and childhood are viral etiology. It is estimated that bacteria cause only $10 \%-30 \%$ of all cases of acute pneumonia. ${ }^{1}$ Rarely the cause of pneumonia in children could be identified, therefore, antibiotic therapy must be empirical, using a drug that will be effective against the most common causes of illness. ${ }^{2}$ A study using lung aspiration technique suggests that $S$. pneumoniae and $H$. influenzae are the most frequent causes of bacterial pneumonia in all age groups. ${ }^{3}$ According to Shann et al. ${ }^{4}$ S. pneumoniae and $H$. influenzae cause most fatal pneumonia in children. The best way to obtain specimen to know the etiology of pneumonia is by 
using lung puncture. Lung puncture yields the highest rate of positive cultures. However, this procedure is an invasive method that exposes the child to serious risks, there have been strong ethical objections to use it in clinical research, especially for a study in the community. According to $\mathrm{WHO}$, isolates to be tested for antimicrobial resistance in the community should be obtained from nasopharyngeal (NP) swabs. Previous studies support the use of NP isolates to determine antimicrobial resistance patterns of isolates from children with pneumonia. ${ }^{3}$

Several antibiotics are effective in treating $S$. pneumoniae and $H$. influenzae infections, including penicillin, ampicillin, amoxycillin, co-trimoxazole and chloramphenicol. However, several studies reported that some strains have developed resistance to one or more of these antimicrobial agents. ${ }^{2}$ The aim of the study is to know the nasopharyngeal bacterial carriage in children with community-acquired pneumonia and the antimicrobial resistance to cotrimoxazole.

\section{Methods}

The study was a part of a study on the management of pneumonia in infants and children in the community, in Bandung, West Java, Indonesia, from September 1999 to June 2000. The study took place in Majalaya subdistrict. Majalaya is a periurban subdistrict, about 30 kilometers South from the city of Bandung, composed of 6 villages, each village with one health center (Puskesmas). Four health centers were selected for the study: Majalaya Baru, Cikaro, Solokan Jeruk and Padamukti.

All children with cough or difficult breathing who came to the health centers were examined by a study physician. All underfive children with pneumonia according to the WHO classification, were enrolled in the study. The field doctor collected a nasopharyngeal swab from the subjects in the Puskesmas. Calcium alginate swabs on flexible aluminium wire shafts were used for this purpose. With the child's head tipped backwards and immobilized, a sterile swab was inserted into a nostril and passed to the nasopharynx. To make sure that the swab has reached the nasopharynx, the shaft should be passed a distance half of that between the nose and the ear. The swab was directly placed in a screw cap tube contains of Amies transport medium. The entire fiber portion of the swab must be covered by the medium. Thereafter, all the tubes were put into an anaerobic jar, and kept in the room temperature before transported to the laboratory in the Medical Research Unit, in Bandung, in the same day, for further examination. In the laboratory, the specimens were inoculated for isolation of bacteriae and tested for resistance to co-trimozaxole.

\section{Results}

During this 9 month study, there were 698 cases of non-severe pneumonia, consisting of 350 (50.1\%) boys and $348(49.9 \%)$ girls, with age between 2 to 59 months. More than $40 \%$ of subjects were infants 2 to 11 months old, and more than three quarters age less than 3 years of age (Table 1 ).

Table 2 shows the naso-pharyngeal swab (NPS) culture results. It is shown that more than $25 \%(177 / 698)$ of the nasopharyngeal specimens yielded bacterial isolates: $120(67.8 \%)$ for $S$. pneumoniae, S. epidermidis and alpha streptococcus 21 (11.9), respectively, Hafnium alive 6 (3.4\%), S aureus $5(2.8 \%)$, N. catarrhalis $2(1.1 \%)$ and $1(0.6 \%)$ for $H$. influenzae and Klebsiella, respectively.

TABLE 1. CHARACTERISTICS OF RESPONDENTS

\begin{tabular}{lrr}
\hline Characteristics & $\mathrm{N}$ & $\%$ \\
\hline 1. Sex & & \\
Boy & 350 & 50.1 \\
Girls & 348 & 49.9 \\
2. Age (months) & & \\
$2-11$ & 284 & 40.7 \\
$12-23$ & 256 & 36.7 \\
$24-35$ & 105 & 15.0 \\
$36-47$ & 38 & 5.4 \\
$48-59$ & 15 & 2.1 \\
\hline
\end{tabular}

TABLE 2. YIELDS OF NASO-PHARYNGEAL SWAB (NPS) CULTURES - PERCENTAGE OF POSITIVE RESULTS

\begin{tabular}{lrc}
\hline Bacteria & $\mathrm{n}$ & $\%$ \\
\hline Streptococcus pneumoniae & 120 & 67.8 \\
Staphylococcus epidermidis & 21 & 11.9 \\
Alpha streptococcus & 21 & 11.9 \\
Hafnia alvei & 6 & 3.4 \\
Staphylococcus aureus & 5 & 2.8 \\
Moraxella catarrhalis & 2 & 1.1 \\
Haemophilus influenzae & 1 & 0.6 \\
Klebsiella pneumoniae & 1 & 0.6 \\
\hline
\end{tabular}


All children received co-trimoxazole for 5 days. Antimicrobial resistance test was conducted for $S$. pneumoniae, more than $48 \%$ showed resistance to cotrimoxazole, $32.7 \%$ intermediate resistance and only 19.1\% were sensitive (Table 3).

TABLE 3. ANTIMICROBIAL RESISTANCE OF S. PNEUMONIAE TO CO-TRIMOXAZOLE

\begin{tabular}{lrr}
\hline Resistance to co-trimoxazole & $\mathrm{N}$ & $\%$ \\
\hline Resistant & 53 & 48.2 \\
Intermediate resistant & 36 & 32.7 \\
Sensitive & 21 & 19.1 \\
\hline Total & 120 & 100.0 \\
\hline
\end{tabular}

\section{Discussion}

Many factors have to be considered to provide optimal management for children with pneumonia, because the etiology is difficult to determine. The majority of lower respiratory infections in children are viral

TABLE 4. YIELDS OF NASOPHARYNGEAL CULTURES, PERCENTAGE OF POSITIVE RESULTS

\begin{tabular}{|c|c|c|c|c|}
\hline & Egypt & Pakistan & Thailand & Vietnam \\
\hline $\begin{array}{l}\text { Number of } \\
\text { Children } \\
\text { Strepto. }\end{array}$ & 1093 & 601 & 1783 & 403 \\
\hline $\begin{array}{l}\text { Pneumoniae } \\
\text { Haemoph. }\end{array}$ & 19.0 & 36.9 & 17.0 & 29.5 \\
\hline $\begin{array}{l}\text { Influenzae } \\
\text { Both }\end{array}$ & 14.0 & 9.1 & 21.0 & 19.6 \\
\hline Bacteria & 41.0 & 27.5 & 18.0 & 4.5 \\
\hline Total & 74.0 & 73.5 & 55.0 & 54.0 \\
\hline
\end{tabular}

Data from WHO, 1995

etiology; and it has been estimated that bacteria caused 10 to $30 \%$ of all causes of pneumonia. ${ }^{4}$ Clinicians must make several decisions to provide optimal management for children with pneumonia. Usually initial therapy is based on the frequency of pathogens in various age groups, local antibiotic resistance patterns of the organisms, clinical presentation, and epidemiological data. ${ }^{3}$ If pneumonia is diagnosed, it must be determined if the child will benefit from antimicrobial therapy and which drug is most appropriate. Several studies show that S. pneumoniae and $H$. influenzae are the most common bacteria caused pneumonia in children outside the newborn period, ${ }^{3,5,6}$ together account for approximately
$80 \%$ of isolates. ${ }^{7}$ In 1988 , the Center for Disease and Control (CDC) Atlanta and WHO, developed a manual on the national surveillance of antimicrobial resistance of $S$. pneumoniae and $H$. influenzae. The manual was field tested in Egypt, Pakistan, Thailand and Vietnam. ${ }^{8}$ The total positive isolates were $74.0 \%$, $73.5 \%, 55.0 \%$, and $54.0 \%$, respectively. Our study found lower results than those studies, $16.6 \%$ bacterial isolates yield positive. Furthermore, they found $H$. influenzae at $14.0 \%, 9.1 \%, 21 \%$, and $19.6 \%$, respectively; and our study found only one $H$. influenzae (1.2\%). A population-based survey of $H$. influenzae type $b$, in healthy children age $0-<25$ months, conducted in Lombok Island, Indonesia, found 32\% (155/484 samples) NP isolates yielded organisms that were presumptively $H$. influenzae. ${ }^{9}$ According to Pechère, $H$. infuenzae type $b$ infections occur predominantly in children ages between 3 months and 3 years in countries where the coverage of $H$. influenzae $b$ vaccine is low. ${ }^{10}$ In the study area, $H$. influenzae $b$ vaccine has not been yet administered. The big difference results need further study, due to many factors influencing the prevalence of bacterial

TABLE 5. RESISTANCE OF S. PNEUMONIAE ISOLATED FROM NASOPHARYNGEAL CULTURES TO CO-TRIMOXAZOLE

\begin{tabular}{llcc}
\hline Study & Laboratory & Number of Strain & Resistance (\%) \\
\hline Egypt * & CDC, Atlanta & 304 & 80.2 \\
Pakistan * & CDC Atlanta & & \\
$\quad$ Urban & & 276 & 77.5 \\
$\quad$ Rural & & 132 & 40.2 \\
Thailand * & Bangkok & 543 & 25.4 \\
Vietnam * & Hanoi & 114 & 52.6 \\
Indonesia & Bandung & 120 & 48.2 \\
\hline
\end{tabular}

* Data from WHO, 1995

carriage in the throat. And also a special procedure is needed for detection of $H$. influenzae.

Several antibiotics such as penicillin, ampicillin, amoxycillin, co-trimoxazole and chloramphenicol are generally effective in treating S. pneumoniae and $H$. influenzae infections. It is important to know the resistance rate of microorganisms to antibiotics for the decision which antibiotics will be used for children with pneumonia. The WHO ARI Program recommends co-trimoxazole for the management of non-severe pneumonia, ${ }^{11}$ and it is also recommended in Indonesia.

Two community studies conducted in Pakistan showed in vivo efficacy of co-trimoxazole in $92 \%$ and $91 \%$ of children with non-severe pneumonia. Another 
study revealed $78.3 \%-79.9 \%$ in vitro resistance to co-trimoxazole among S. pneumoniae isolates. ${ }^{12} \mathrm{Nev}$ ertheless, co-trimoxazole is still recommended in $\mathrm{Pa}$ kistan. Our study showes a lower percentage resistance to co-trimoxazole compared to Egypt and Pakistan (urban), but higher than Thailand and rural area in Pakistan. It is almost similar with the results from Vietnam. Although many studies reveal high levels of resistance of S. pneumoniae to co-trimoxazole, however, in vivo response is still good.

To sum up, the study shows that the positive bacteria isolates is low compared to the other studies. S pneumoniae resistance to co-trimoxazole are lower compared to Egypt, Pakistan, and similar with Vietnam but higher than in Thailand. It seems that $H$. influenzae is not an important cause of pneumonia in that area. Nevertheless, further study is needed to know the role of bacteria as the cause of community acquired pneumonia.

\section{Acknowledgments}

Infectious Diseases and Environmental Health, Department of Health, Republic of Indonesia. We also thank the head and staff of P2- ISPA Departemen Kesehatan, the Head and all staffs of Puskesmas in Majalaya Baru, Cikaro, Solokan Jeruk and Padamukti, and the ARI working goup in the Research Unit.

\section{References}

1. Turner RB, Lande AE, Chase P, Hilton N, Weinberg D. Pneumonia in pediatric outpatients: Cause and clinical manifestations. J Pediatr 1987;111:194-200
2. World Health Organization (WHO). Manual for the National Surveillance of antimicrobial resistance of $S$ pneumoniae and $\mathrm{H}$ influenzae: Epidemiologycal and microbiological methods, WHO Geneva and CDC Atlanta, 1994

3. Harris JS. Antimicrobial therapy of pneumonia in infants and children. Semin Respir Infect 1996; 11:139-47.

4. Shann F, Woolcock A, Black R, Cripps A, Foy H, Harris M, D'Souza R. Introduction: Acute respiratory infections - The forgotten Pandemic. CID 1999; 28:189. 91.

5. Shann F. Etiology of severe pneumonia in children in developing countries. Pediatr Infect Dis J 1986;5:247-52.

6. Schidlow DV, Callahan CW. Pneumonia. Pediatr Rev 1996:17:300-9.

7. De Valk H. Surveillance of respiratory bacteria drug resistance. Seminar ARI, Ciloto, 1996.

8. World Health Organization (WHO). Programe for the control of acute respiratory infections. Surveillance of respiratory bacteria drug resistance, 1995

9. Gessner BD, Sutanto A, Steinhoff M, Soewignjo S, Widjaya A, Nelson C, Arjoso S. Population-based survey of Haemophilus influenzae type b nasopharyngeal carriage prevalence in Lambok Island, Indonesia. Pediatr Infect Dis J 1998;17:S179-82

10. Pechere JC. Editor. Community acquired pneumonia in children. International forum series. Cambridge Medical Publications, 1995

11. World Health Organization (WHO). Antibiotics in the treatment of acute respiratory infections in young children. 1990;10:2

12. Qazi SA. Antibiotic strategies for developing countries: Experience with acute respiratory infections in Pakistan. CID 1999; 28:214-8 